Address for Correspondence: Prof. Patrick M. Honore, Department of Intensive Care, Intensive Care Medicine, University Hospital, Universitair Ziekenhuis Brussel, Vrije Universiteit Brussel, Laarbeeklaan 101, B-1090 Brussels, Belgium.

E-mail: patrick.Honore@uzbrussel.be

\begin{tabular}{|l|}
\hline Access this article online \\
\hline $\begin{array}{l}\text { Website: } \\
\text { www.intern-med.com }\end{array}$ \\
\hline DOI: \\
10.1515/jtim-2013-0007 \\
\hline Quick Response Code: \\
\hline \\
\\
\hline
\end{tabular}

\section{New insights in prevention and treatment of sepsis-induced acute kidney injury}

Patrick M. Honore ${ }^{1^{*}}$, Rita Jacobs ${ }^{1}$, Olivier Joannes-Boyau ${ }^{2}$, Willem Boer ${ }^{3}$, Elisabeth De Waele ${ }^{1}$, Viola Van Gorp ${ }^{1}$, Herbert D. Spapen ${ }^{1}$

IIntensive Care Medicine, Intensive Care Dept, Universitair Ziekenhuis Brussel, Vrije Universiteit Brussel, Brussels, Belgium; ' ${ }^{2} \mathrm{CU}$ Consultant, Haut Leveque University Hospital of Bordeaux, University of Bordeaux 2, Pessac, France; ${ }^{3}$ Department of Anaesthesiology and Critical Care Medicine, Ziekenhuis Oost-Limburg, Genk, Belgium

\title{
ABSTRACT
}

Sepsis-induced acute kidney injury (SAKI) remains an important challenge for intensive care unit clinicians. We reviewed current available evidence regarding prevention and treatment of SAKI thereby incorporating some major recent advances and developments. Prevention includes early and ample administration of "balanced" crystalloid solutions such as Ringer's lactate. For monitoring of renal function during resuscitation, lactate clearance rate is preferred above $\mathrm{S}_{\mathrm{cv}} \mathrm{O}_{2}$ or renal Doppler. Aiming at high central venous pressures seems to be deleterious in light of the novel "kidney afterload" concept. Noradrenaline is the vasopressor of choice for preventing SAKI. Intra-abdominal hypertension, a potent trigger of acute kidney injury in postoperative and trauma patients, should not be neglected in sepsis. Renal replacement therapy (RRT) must be started early in fluid-overloaded patients refractory to diuretics. Continuous RRT (CRRT) is the preferred modality in hemodynamically unstable SAKI but its use in more stable SAKI is increasing. In the absence of hypervolemia, diuretics should be avoided. Antimicrobial dosing during CRRT needs to be thoroughly reconsidered to assure adequate infection control.

Key words: acute kidney injury, bedside management, medical therapies, prevention, sepsis

\section{PREVENTION OF SEPSIS-INDUCED ACUTE KIDNEY INJURY (AKI)}

\section{Fluid resuscitation}

Aim

The old "credo" stating that fluid harms the lung but benefits the kidney should be revised. ${ }^{[1]}$ Liberal fluid administration is of key importance to optimize systemic hemodynamics in patients with sepsisinduced acute kidney injury (SAKI). Yet, ongoing controversy exists about efficacy, nature, extent and duration of fluid resuscitation in septic shock. ${ }^{[2]}$ In fact, intensive care unit physicians are faced with a "double-edged" fluid dilemma. Volume resuscitation is indeed essential to restore and maintain cardiac output and oxygen delivery. Sustained or unrestricted infusion of fluids, however, will cause tissue edema which may significantly contribute to organ dysfunction. On the other hand, too rapid or excessive fluid removal with diuretics or extracorporeal techniques might cause severe hypovolemia and recurrent renal injury. An optimal stepwise approach is to guarantee a smooth transition from initial unrestricted fluid resuscitation (positive fluid balance), managing a state of equilibrium (steady fluid balance) and finally assuring an appropriate rate of fluid removal (negative fluid balance). ${ }^{[3]}$ This process is kept on track by meticulous and serial assessments of fluid handling aiming at well-defined cardiovascular and renal targets. Patients developing SAKI are evidently more susceptible to fluid accumulation and thus particularly prone to its harmful consequences. ${ }^{[4]}$ Early use of 
renal replacement therapy (RRT) in this population will offer the best possible outcome.

\section{Type of fluids}

Hypotension and hypovolemia during sepsis may cause or worsen AKI. Increasing evidence suggests that isotonic crystalloid solutions should be used instead of colloids for initial intravascular volume expansion in septic patients at risk for AKI. ${ }^{[5,6]}$ Timing and amount of volume to prevent SAKI (and other organ damage) remain a matter of debate. Although early aggressive fluid resuscitation is considered to be beneficial, ${ }^{[7]}$ observational studies in critically ill patients with SAKI have linked fluid overload to increased mortality and reduced kidney recovery. ${ }^{[8]}$ The substantial risk for induction of osmotic nephrosis (by pinocytosis in the renal tubules) strongly pleads against the use of hydroxyethyl starch and dextran solutions. ${ }^{[9]}$ Balanced crystalloid perfusions (e.g., Ringer's lactate) may be preferred above isotonic salt solutions. ${ }^{[10]}$ The latter contain a high chloride load which may be detrimental for the kidney. ${ }^{[11]}$

\section{Albumin}

It is a common belief that albumin $5 \%$ or $20 \%$ solutions, through a hyperoncotic effect, will force excess water back from the tissues into the endovascular space. ${ }^{[12]}$ Surprisingly, this has never been evidenced! On the contrary, it was recently shown that albumin infusion rather promotes extracellular fluid overload without improving hypovolemia. ${ }^{[13]}$ Accordingly, more data are needed before albumin infusion can be recommended for prevention of SAKI.

\section{Early use of continuous RRT (CRRT)}

Fluid overload definitely increases kidney edema and enhances severity and irreversibility of SAKI. ${ }^{[3,14]}$ Therefore, timely use of CRRT in cases of fluid overload that are poorly responding or refractory to diuretics might be a reasonable approach to attenuate or control SAKI. ${ }^{[14]}$ CRRT reduced mortality in acutely ill fluid-overloaded children. ${ }^{[15]}$

\section{Monitoring}

\section{Renal doppler}

The kidneys receive approximately $25 \%$ of total blood flow of which they use less than half mainly because of intricate intrarenal shunting. ${ }^{[16]}$ Therefore, monitoring limited to global evaluation of renal blood flow tells very little about the adequacy of oxygen supply to the kidneys. ${ }^{[17]}$ As a consequence, renal Doppler is not a reliable tool to assess oxygen supply and its potential response to fluid loading. ${ }^{[17]}$ Future research should focus on the renal microcirculation.
Central venous oxygen saturation $\left(\mathrm{S}_{\mathrm{cv}} \mathrm{O}_{2}\right)$ and lactate clearance rate

It has been suggested that $\mathrm{S}_{\mathrm{cv}} \mathrm{O}_{2}$ values exceeding $70 \%$ are needed to prevent AKI. Recent studies, however, did not find any correlation between restoration of systemic hemodynamics or increasing oxygen supply and occurrence of AKI ${ }^{[18]}$ Kidney function is less dependent on enhanced oxygen delivery but more sensible to mean arterial perfusion pressure. This explains why noradrenaline better preserves kidney function than dobutamine ${ }^{[19]}$ and lactate clearance rate more adequately mirrors kidney perfusion than $\mathrm{S}_{\mathrm{cv}} \mathrm{O}_{2} \cdot{ }^{[20]}$

\section{Central venous pressure (CVP) and the "afterload"} of the kidney

For decades, clinicians have thought that a high filling pressure was imperative to attenuate the risk for AKI. ${ }^{[18,21]}$ Indeed, by analogy with the hart and his starling curve, we believe that only preload was of importance for preserving the kidney by increasing blood volume and flow to the kidney. In the recent years, again by analogy with the hart physiology, it was shown that a certain level of CVP was indeed beneficial for the kidney but could also be detrimental by increasing venous congestion and blocking venous return of the kidney. Venous return has a major impact on kidney function. At this was happening after the kidney, it was named "afterload "of the kidney again by analogy with the hart physiology. Chinese investigators recently demonstrated the negative impact of high CVP on the kidney function. In fact, they showed an increased incidence of AKI at higher levels of CVP. ${ }^{[21]}$ A possible explanation of this controversial finding could be unexpected changes in kidney afterload resulting in deleterious venous congestion. ${ }^{[18]}$ In view of these findings, a CVP of 8 to10 $\mathrm{mmHg}$ may be ideal for adequate kidney perfusion while a CVP above $12 \mathrm{mmHg}$ could be harmful. ${ }^{[18,21,22]}$

\section{Differentiating transient (functional) from structural SAKI}

Low fractional excretions of sodium $\left(\mathrm{FE}_{\mathrm{Na}}\right)$ and urea $\left(\mathrm{FE}_{\mathrm{Urea}}\right)$ are highly prevalent during the initial phase of sepsis. Oliguria is an earlier sign of impending SAKI than the increase in serum creatinine. A combination of a high $\mathrm{FE}_{\mathrm{Na}}$ and a low $\mathrm{FE}_{\mathrm{Urea}}$ value is associated with intrinsic SAKI whereas high values for both $\mathrm{FE}_{\mathrm{Na}}$ and $\mathrm{FE}_{\mathrm{Urea}}$ are strongly predictive for transient or functional SAKI. ${ }^{[23]}$ Nevertheless, these biochemical parameters do not perform as well as specific biomarkers of SAKI. ${ }^{[2]}$ Among the most recent biomarker assays, the neutrophil gelatinase associated lipocalin and the nephrocheck test are promising tools for bedside differentiation between transient and structural SAKI. ${ }^{[25,26]}$ However, due to their limited availability, these biomarkers cannot be recommended for guiding therapy. 


\section{Transfusion policy}

From a physiological viewpoint, a hematocrit level of $30 \%$ was considered to be an optimal target within the prevention measures for SAKI. ${ }^{[27]}$ A recent retrospective study, however, showed that red blood cell transfusion in non-bleeding critically ill patients with moderate anemia and without shock was associated with higher nosocomial infection rates, more AKI and increased mortality. ${ }^{[28]}$ This apparent "transfusion-related AKI" could be coined by the acronym "TRAKI" in analogy to the recognized "TRALI" which stands for "transfusion related acute lung injury". [2] Regarding prevention of SAKI, a hematocrit level of $25 \%$ may be a more realistic target. ${ }^{[28]}$ Interestingly, the introduction of citrate as an anticoagulant during CRRT has resulted in significantly lower transfusion needs. A potential beneficial role of citrate on preservation and/or recovery of SAKI has been suggested ${ }^{[30]}$ but needs confirmation.

\section{Vasopressive and inotropic support}

As discussed earlier, renal flow and oxygen supply have been wrongly considered to be determining players in the pathophysiology of SAKI. ${ }^{[18,21]}$ SAKI was thought to result from ischemia due to a reduced blood flow ${ }^{[31]}$ and therapy aimed to increase filling pressures (i.e., fluid administration) and cardiac output (i.e., inotropic support). This concept was challenged by Di Giantomasso et al. who demonstrated in an experimental hyperdynamic septic shock model that noradrenaline (i.e., vasopression!) significantly increased global and medullary renal blood flow and restored renal vascular tone toward normal. ${ }^{[32]}$ Vasopressin does not offer the advantage over noradrenaline. The vasopressin and septic shock trial did not show any difference in incidence of AKI or need for RRT with the use of vasopressin. ${ }^{[33]}$

\section{Intra-abdominal hypertension}

Post-chirurgical incidence

Intra-abdominal hypertension (IAH) and its most dreaded presentation, the abdominal compartment syndrome (ACS), are frequently associated with AKI in surgical and traumatic patients. Because signs and symptoms are non-specific and laboratory and imaging studies often remain inconclusive, the diagnosis of AKI as a manifestation of IAH requires a high index of clinical suspicion. Early recognition and treatment improve clinical outcome. ${ }^{[34]}$ IAH has also been described in up to one-third of cardiac surgery patients where it was found to be strongly associated with higher baseline intra-abdominal pressure (IAP), increased CVP, positive fluid balance, extracorporeal circulation, use of vasoactive drugs and AKI. Determinants of IAH therefore need accurate assessment before and after surgery. Patients presenting any known risk factor must be closely monitored during the perioperative period. In this context, the baseline IAP may be a valuable early warning parameter for IAH. ${ }^{[34]}$
Incidence during SAKI and medical conditions

Once considered mostly a postsurgical condition, IAH and ACS are now thought to increase morbidity and mortality in many patients receiving medical intensive care. Factors predisposing to IAH/ACS include sepsis, large volume fluid resuscitation, polytransfusion, mechanical ventilation with high intrathoracic pressure and acidosis, among others. Transduction of bladder pressure is the gold standard for measuring IAP and several nonsurgical methods can help reduce IAP. The role of RRT for volume management is not well-defined but may be beneficial in some cases. As septic patients mostly require substantially larger amounts of fluids, they are more prone to develop IAH. ${ }^{[34,35]}$ Consequently, any impact of IAH on development and progression of SAKI must be timely considered and anticipated. It is op upmost importance to detect early on IAH in post cardiac surgery as they will be more prone to develop very quickly IAH by gathering both group risk factors. Lastly, the role of RRT for volume management may be beneficial in some cases ${ }^{[35]}$

\section{TREATMENT OF SEPSIS-INDUCED AKI}

\section{Timing of CRRT}

CRRT should be initiated upfront when fluid overload does insufficiently respond or remains refractory to a diuretic challenge. ${ }^{[3,14,15]}$ In established SAKI, the recently published IVOIRE study ${ }^{[36]}$ suggested to start CRRT at risk, injury, failure, loss, end injury level. Starting at this stage indeed correlated with a very low mortality at 90 days. ${ }^{[36]}$ More data are needed before this approach can be recommended.

\section{Renal replacement modalities}

A study by Prowle and Bellomo et al. recently demonstrated that hemodynamically unstable patients with SAKI treated with CRRT remained significantly less dialysisdependent (5\% vs. $25 \%$ ) than those receiving IHD. ${ }^{[37]}$ Therefore, CRRT is recommended as first-line therapy in this population. A recent meta-analysis suggested superiority of CRRT to IHD in terms of renal recovery in patients without cardiovascular instability. ${ }^{[38]}$ A prospective randomized study is needed to confirm this observation. High-volume hemofiltration has no place in the treatment of SAKI ${ }^{[36,39]}$ now-a-days. In current practice a dialysis dose of $35 \mathrm{ml} / \mathrm{kg} / \mathrm{h}$ is prescribed to ascertain delivery of at least $25 \mathrm{~mL} / \mathrm{kg} / \mathrm{h}$.

\section{Role of diuretics}

The use of diuretics to provoke or increase urine production in the absence of hypervolemia is associated with increased mortality ${ }^{[40]}$ and should be discouraged. A furosemide stress test has been proposed for early 
assessment of tubular function. The test showed robust predictive capacity for identifying patients at risk for severe and progressive AKI but needs further validation. ${ }^{[41]}$ No comparable test predicts renal recovery.

\section{Antimicrobial dosing during CRRT}

The use of CRRT significantly influences the pharmacokinetic and-dynamic behavior of most antimicrobial agents. This is insufficiently anticipated by currently recommended dosing guidelines. Patients are particularly at risk for underdosing, which may cause treatment failure and enhanced resistance. An in-depth discussion of this topic is beyond the scope of this article. As you can see in Table 1, dose adaptations for some major antibiotic and antifungal drugs during CRRT are proposed.

\section{CONCLUSIONS}

Prevention of SAKI starts with early and adequate fluid resuscitation. Balanced crystalloid solutions with lower chloride load (e.g., Ringer's lactate) are preferred. Synthetic colloids should be abandoned. A lactate clearance test is a better tool for monitoring kidney perfusion than $\mathrm{S}_{\mathrm{cv}} \mathrm{O}_{2}$ or renal Doppler. In light of the novel "kidney afterload" concept, a high filling pressure should be avoided. Noradrenaline is the vasopressor of choice for preventing SAKI. IAH is a potential, yet often overlooked, trigger of SAKI. Early initiation of RRT is recommended when fluid overload is refractory to diuretics. CRRT is the modality of choice in hemodynamically unstable SAKI but may also offer better outcome than IHD in stable SAKI. Except for life-threatening hypervolemia, diuretics have no place

\begin{tabular}{|c|c|c|}
\hline Antibiotic/Antifungal & Loading dose & Maintenance dose \\
\hline Amikacin & $30-35 \mathrm{mg} / \mathrm{kg}$ & TDM \\
\hline Meropenem & $2 \mathrm{~g}$ & $2 \mathrm{~g}$ over $3 \mathrm{~h}$ tid \\
\hline Piperacillin-tazobactam & $4 \mathrm{~g} / 0.5 \mathrm{~g}$ & $16 \mathrm{~g} / 2 \mathrm{~g}(\mathrm{Cl})$ \\
\hline Vancomycin & $\begin{array}{l}35 \mathrm{mg} / \mathrm{kg} \\
\text { over } 4 \mathrm{~h}\end{array}$ & $\begin{array}{c}30-35 \mathrm{mg} / \mathrm{kg} \\
(\mathrm{TDM}=25-30 \mathrm{mg} / \mathrm{L})\end{array}$ \\
\hline Teicoplanin & $\begin{array}{c}3 \times 15 \mathrm{mg} / \mathrm{kg} \\
\text { every } 12 \mathrm{~h}\end{array}$ & $600 \mathrm{mg}$ od \\
\hline Linezolid & & $600 \mathrm{mg}$ tid \\
\hline Ciprofloxacin & $800 \mathrm{mg}$ & $400 \mathrm{mg}$ tid \\
\hline Tigecyclin & $150 \mathrm{mg}$ & $100 \mathrm{mg}$ bid \\
\hline Colistin & $9 \mathrm{MIU}$ & 4, $5 \mathrm{MIU}$ tid \\
\hline Voriconazole & $8 \mathrm{mg} / \mathrm{kg} \mathrm{bid}$ & $6 \mathrm{mg} / \mathrm{kg} \mathrm{bid}$ \\
\hline Fluconazole & & $600 \mathrm{mg}$ bid \\
\hline Cefepime & & $2 \mathrm{~g} \mathrm{tid}$ \\
\hline Gentamycin & & $7 \mathrm{mg} / \mathrm{kg}$ od \\
\hline Bactrim & $\begin{array}{c}1200 \mathrm{mg} / 240 \mathrm{mg} \\
(3 \mathrm{amp})\end{array}$ & $\begin{array}{c}800 \mathrm{mg} / 160 \mathrm{mg} \\
(2 \mathrm{amp}) \mathrm{tid}\end{array}$ \\
\hline Clindamycin & & 900 mg qid \\
\hline
\end{tabular}

TDM:Therapeutic drug monitoring, od: Oncedaily, bid: Twice daily, tid: Threetimes daily, qid: Four times daily, AMP: Ampulles, $\mathrm{Cl}$ : Confidence interval in the prevention or treatment of SAKI. Antimicrobial therapy requires special attention and adaptation during CRRT.

\section{REFERENCES}

1. Prowle JR, Bellomo R. Fluid administration and the kidney. Curr Opin Crit Care 2013;19:308-14.

2. De la Puente-Diaz de Leon VM, Rivero-Sigarroa E, Domiguez-Cherit G, Namendys-Silva SA. Fluid therapy in severe sepsis and septic shock. Crit Care Med 2013;41:e484-5.

3. Modem V, Thompson M, Gollhofer D, Dhar AV, Quigley R. Timing of continuous renal replacement therapy and mortality in critically Ill children. Crit Care Med 2013. [Epub ahead of print]

4. Prowle JR, Kirwan CJ, Bellomo R. Fluid management for the prevention and attenuation of acute kidney injury. Nat Rev Nephrol 2013. [Epub ahead of print]

5. Perner A, Haase N, Guttormsen AB, Tenhunen J, Klemenzson G, Åneman A, et al. Hydroxyethyl starch 130/0.42 versus Ringer's acetate in severe sepsis. N Engl J Med 2012;367:124-34.

6. Mutter TC, Ruth CA, Dart AB. Hydroxyethyl starch (HES) versus other fluid therapies: Effects on kidney function. Cochrane Database Syst Rev 2013;7:CD007594.

7. Bouchard J, Soroko SB, Chertow GM, Himmelfarb J, Ikizler TA, Paganini EP, et al. Fluid accumulation, survival and recovery of kidney function in critically ill patients with acute kidney injury. Kidney Int 2009;76:422-7.

8. Payen D, de Pont AC, Sakr Y, Spies C, Reinhart K, Vincent JL. Sepsis occurrence in acutely Ill patients (SOAP) investigators. Crit Care 2008;12:R74.

9. Wiedermann CJ, Joannidis M. Accumulation of hydroxyethyl starch in human and animal tissues: A systematic review. Intensive Care Med 2013. [Epub ahead of print]

10. Yunos NM, Bellomo R, Hegarty C, Story D, Ho L, Bailey M. Association between a chloride-liberal vs chloride-restrictive intravenous fluid administration strategy and kidney injury in critically ill adults. JAMA 2012;308:1566-72.

11. Waikar SS, Winkelmayer WC. Saving the kidneys by sparing intravenous chloride? JAMA 2012;308:1583-5.

12. Myburgh JA, Finfer S. Albumin is a blood product too-is it safe for all patients? Crit Care Resusc 2009;11:67-70.

13. Kumar R, Kumar S, Lata S. Albumin infusion may deleteriously promote extracellular fluid overload without improving circulating hypovolemia in patients of advanced cirrhosis with diabetes mellitus and sepsis. Med Hypotheses 2013;80:452-5.

14. Fülöp T, Pathak MB, Schmidt DW, Lengvárszky Z, Juncos JP, Lebrun $\mathrm{CJ}$, et al. Volume-related weight gain and subsequent mortality in acute renal failure patients treated with continuous renal replacement therapy. ASAIO J 2010;56:333-7.

15. Goldstein SL. Advances in pediatric renal replacement therapy for acute kidney injury. Semin Dial 2011;24:187-91.

16. Beierwaltes WH, Harrison-Bernard LM, Sullivan JC, Mattson DL. Assessment of renal function; clearance, the renal microcirculation, renal blood flow, and metabolic balance. Compr Physiol 2013;3:165-200.

17. Dewitte A, Coquin J, Meyssignac B, Joannès-Boyau O, Fleureau C, Roze $\mathrm{H}$, et al. Doppler resistive index to reflect regulation of renal vascular tone during sepsis and acute kidney injury. Crit Care 2012;16:R165.

18. Legrand M, Dupuis C, Simon C, Gayat E, Mateo J, Lukaszewicz AC, et al. Association between systemic hemodynamics and septic acute kidney injury in critically ill patients: A retrospective observational study. Crit Care 2013;17:R278.

19. Bellomo R, Wan L, May C. Vasoactive drugs and acute kidney injury. Crit Care Med 2008;36 4 Suppl:S179-86.

20. Yu B, Tian HY, Hu ZJ, Zhao C, Liu LX, Zhang Y, et al. Comparison of the effect of fluid resuscitation as guided either by lactate clearance rate or by central venous oxygen saturation in patients with sepsis. Zhonghua Wei Zhong Bing Ji Jiu Yi Xue 2013;25:578-83.

21. Chen XK, Li SW, Liu DW, Yang RL, Zhang HM, Zhang H, et al. Effects of central venous pressure on acute kidney injury in septic shock. Zhonghua Yi Xue Za Zhi 2011;91:1323-7. 
22. Legrand M, Dupuis C, Simon C, Gayat E, Mateo J, Lukaszewicz AC, et al. Association between systemic hemodynamics and septic acute kidney injury in critically ill patients: A retrospective observational study. Crit Care 2013;17:R278

23. Vanmassenhove J, Glorieux G, Hoste E, Dhondt A, Vanholder R, Van Biesen W. Urinary output and fractional excretion of sodium and urea as indicators of transient versus intrinsic acute kidney injury during early sepsis. Crit Care 2013;17:R234.

24. Honoré PM, Jacobs R, Joannes-Boyau O, Boer W, De Waele E, Van Gorp V, et al. Fractional excretion of urea to differentiate transient from persistent acute kidney injury: Should we still trust old tools in the biomarker era? J Crit Care 2012;27:514-5.

25. Honore PM, Jacobs R, Joannes-Boyau O, Verfaillie L, De Regt J, Van Gorp V, et al. Biomarkers for early diagnosis of AKI in the ICU: Ready for prime time use at the bedside? Ann Intensive Care 2012;2:24.

26. Kashani K, Al-Khafaji A, Ardiles T, Artigas A, Bagshaw SM, Bell M, et al. Discovery and validation of cell cycle arrest biomarkers in human acute kidney injury. Crit Care 2013;17:R25.

27. Konrad FM, Mik EG, Bodmer SI, Ates NB, Willems HF, Klingel K, et al. Acute normovolemic hemodilution in the pig is associated with renal tissue edema, impaired renal microvascular oxygenation, and functional loss. Anesthesiology 2013;119:256-69.

28. Leal-Noval SR, Muñoz-Gómez M, Jiménez-Sánchez M, Cayuela A, Leal-Romero M, Puppo-Moreno A, et al. Red blood cell transfusion in non-bleeding critically ill patients with moderate anemia: Is there a benefit? Intensive Care Med 2013;39:445-53.

29. Jaworski K, Maślanka K, Kosior DA. Transfusion-related acute lung injury: A dangerous and underdiagnosed noncardiogenic pulmonary edema. Cardiol J 2013;20:337-44.

30. Oudemans-van Straaten HM, Bosman RJ, Koopmans M, van der Voort PH, Wester JP, van der Spoel JI, et al. Citrate anticoagulation for continuous venovenous hemofiltration. Crit Care Med 2009;37:545-52.

31. Schrier RW, Wang W. Acute renal failure and sepsis. N Eng1 J Med 2004;351:159-69.

32. Di Giantomasso D, Morimatsu H, May CN, Bellomo R. Intrarenal blood flow distribution in hyperdynamic septic shock: Effect of norepinephrine. Crit Care Med 2003;31:2509-13.
33. Russell JA, Walley KR, Singer J, Gordon AC, Hébert PC, Cooper DJ, et al. Vasopressin versus norepinephrine infusion in patients with septic shock. N Engl J Med 2008;358:877-87.

34. Dalfino L, Sicolo A, Paparella D, Mongelli M, Rubino G, Brienza N. Intra-abdominal hypertension in cardiac surgery. Interact Cardiovasc Thorac Surg 2013;17:644-51.

35. Mohmand H, Goldfarb S. Renal dysfunction associated with intraabdominal hypertension and the abdominal compartment syndrome. J Am Soc Nephrol 2011;22:615-21.

36. Joannes-Boyau O, Honoré PM, Perez P, Bagshaw SM, Grand H, Canivet $\mathrm{JL}$, et al. High-volume versus standard-volume haemofiltration for septic shock patients with acute kidney injury (IVOIRE study): A multicentre randomized controlled trial. Intensive Care Med 2013;39:1535-46.

37. Prowle JR, Bellomo R. Continuous renal replacement therapy: Recent advances and future research. Nat Rev Nephrol 2010;6:521-9.

38. Schneider AG, Bellomo R, Bagshaw SM, Glassford NJ, Lo S, Jun M, et al. Choice of renal replacement therapy modality and dialysis dependence after acute kidney injury: A systematic review and metaanalysis. Intensive Care Med 2013;39:987-97.

39. Zhang P, Yang Y, Lv R, Zhang Y, Xie W, Chen J. Effect of the intensity of continuous renal replacement therapy in patients with sepsis and acute kidney injury: A single-center randomized clinical trial. Nephrol Dial Transplant 2012;27:967-73.

40. Mehta RL, Pascual MT, Soroko S, Chertow GM, PICARD Study Group. Diuretics, mortality, and nonrecovery of renal function in acute renal failure. JAMA 2002;288:2547-53.

41. Chawla LS, Davison DL, Brasha-Mitchell E, Koyner JL, Arthur JM, Shaw AD, et al. Development and standardization of a furosemide stress test to predict the severity of acute kidney injury. Crit Care 2013;17:R207.

How to cite this article: Honore PM, Jacobs R, Joannes-Boyau O, Boer W, De Waele E, Van Gorp V, Spapen HD. New insights in prevention and treatment of sepsis-induced acute kidney injury. J Transl Intern Med 2013; 1(1): 23-7.

Source of Support: Nil, Conflict of Interest: None declared 